\title{
Studies on the diagnosis and pathogenesis of Raynaud's phenomenon of occupational origin
}

\author{
AKIRA OKADA, TAKAMASA YAMASHITA, CHIEKO NAGANO, \\ TOSHIKO IKEDA, AKIRA YACHI, and SHIGERU SHIBATA \\ Department of Public Health and Department of Internal Medicine (Section 1), \\ Sapporo Medical College, Sapporo, and Department of Radiology, Tonan Hospital, Sapporo, \\ Japan
}

\begin{abstract}
Okada, A., Yamashita, T., Nagano, C., Ikeda, T., Yachi, A., and Shibata, S. (1971). Brit. J. industr. Med., 28, 353-357. Studies on the diagnosis and pathogenesis of Raynaud's phenomenon of occupational origin. Experiments were designed to investigate tests for the diagnosis of Raynaud's phenomenon of occupational origin between attacks and to investigate the pathogenesis, particularly with reference to factors in the patient. The fingertip blood flow was low not only in subjects with Raynaud's phenomenon (positive group) but also in other users of vibrating tools who did not have Raynaud's phenomenon (negative group). This criterion combined with urinary vanillyl mandelic acid and haptoglobin was examined by analysis of discriminant function. The probability of false discrimination was $3 \%$. Histamine iontophoresis performed after noradrenalin iontophoresis with subsequent comparison of pulse wave amplitudes is useful for identification of the positive group. Haptoglobin was significantly increased and the subjects in whom IgM was increased formed a high proportion of the positive group.
\end{abstract}

Loriga (1911, 1934) and others have reported Raynaud's phenomenon, or finger blanching, in men working with vibrating tools. This phenomenon has also been named 'dead finger, white finger' (Hamilton, 1918) and 'traumatic vasospastic disease of the hand' (Gurdjian and Walker, 1945). Agate (1949) suggested the name 'Raynaud's phenomenon of occupational origin'.

As well as Raynaud's phenomenon the effects of vibration include neuritis and damage of the bones, joints, and muscles. It is not yet clear whether these latter effects are secondary to disorder of the blood supply or whether they occur independently. Whereas it is not difficult to diagnose Raynaud's phenomenon during an attack, it is less easy to be sure of the diagnosis when the subject is seen between attacks. If it were possible to screen the subjects to determine whether or not they would be subject to Raynaud's phenomenon before it appears, this early detection would be valuable in the supervision of the health of users of vibrating tools. In the present paper we report an investigation into the early detection of Raynaud's phenomenon before the appearance of symptoms.

There have been two opinions on the pathogenesis of Raynaud's disease. Lewis and Pickering (1934; Lewis, 1938) considered that it was attributable to a 'local fault' in the blood vessels, but the others have emphasized 'overactivity of the sympathetic nervous system'. Unlike Raynaud's disease, the pathogenesis of Raynaud's phenomenon of occupational origin has not been clarified. Examination of the differences between individuals is also necessary, because some users of vibrating tools are not affected, some are affected only slightly, and some only after a long period of work. To explain these individual differences, the serum proteins were analysed and an immunological basis was explored. Our study sought to explore those factors in the individual concerned with the occurrence of Raynaud's phenomenon. 


\section{Methods}

Circulatory function was investigated by the fingertip blood flow, photomicrography of the capillary vessels, and iontophoresis. For the investigation of the activity of the sympathetic nervous system the excretion of vanillylmandelic acid (VMA) in urine was determined quantitatively. Electromyography, $x$-rays of the joints of the bones, and analysis of serum protein were also performed.

Except for iontophoresis, the investigations were carried out on 13 chain-saw workers in whom Raynaud's phenomenon was confirmed, called the Raynaud's phenomenon positive group, and on eight chain-saw workers who were not affected by Raynaud's phenomenon as a negative group. As well as the above subjects, seven healthy researchers were used in the studies of fingertip blood flow and VMA excretion in urine. For the study of iontophoresis, two groups, one Raynaud's phenomenon positive and the other negative, each having five subjects, were used. All the investigations were carried out between attacks.

The fingertip blood flow was measured on the third finger by the method of Winsor (1959) with the other hand immersed in cold water $\left(4^{\circ} \mathrm{C}\right)$. The capillary vessels of the skin were investigated by FSC photomicrography. Urinary VMA was analysed by the method of SandlerMiyake (Miyake, 1961).

The electromyogram was investigated by the observation of complex NMU voltages in both hands. X-ray films of the hands, forearms, wrist joints, and elbow joints were taken. The electromyograms and $x$-rays were interpreted by one of us (S.S.) without any knowledge of the clinical state of the subjects. The apparatus for iontophoresis consisted of a fingerstall with a copper disc attached to the inner tip as the anode, a 45-volt battery, ammeter, variable resistor $(5 \mathrm{~K}-500 \mathrm{~K} \Omega)$, and the cathode attached to the ipsilateral forearm. The third finger of the left hand was examined, because Raynaud's phenomenon appeared in that finger. As pain was felt if the current was increased too rapidly, the current was started at $0.5 \mathrm{~mA}$ and increased by $0.1 \mathrm{~mA}$ every two minutes until it was $1.9 \mathrm{~mA}$ at the end. The method of iontophoresis was as follows: First a solution of $0.1 \%$ noradrenalin was introduced by the above procedure, followed by a solution of $0.5 \%$ histamine in the same way.

In the analysis of the serum proteins the main items measured were: serum total protein analysed by a hand protein refractometer, serum albumin, fractions of $\alpha_{1-}, \alpha_{2^{-}}, \beta-$, and $\gamma$-globulin fractionated by cellulose acetate electrophoresis and calculated from the ratio of each fraction; serum haptoglobin fractionated by cellulose acetate electrophoresis and expressed by the weight of haemoglobin which combined with haptoglobin, and immunoglobin G (IgG), immunoglobin A (IgA), immunoglobulin $\mathbf{M}$ (IgM) analysed by the single radial diffusion method. The normal range of immunoglobulin was established as the $2 \sigma$ range of the average calculated as $100 \%$. These data were obtained from 60 healthy men and women 20 to 50 years of age. Besides serum protein analysis, cold haemagglutination reaction (which was considered positive when the titre was above 64), RA-test, CRP (C-reactive protein, by agar diffusion sedimentation method), and cryoglobulin (by Ouchterlony method) were carried out.
Results

\section{Fingertip blood flow}

Figure 1 shows the change of fingertip blood flow determined over 12 minutes ( 2 minutes' immersion and 10 minutes after immersion). Throughout, the fingertip blood flow was lower than in the controls in both groups (Raynaud's phenomenon positive and negative). Both groups also made a slow recovery. The value in the positive group was always slightly lower than in the negative but this was not statistically significant. The fingertip blood flow was low in all the chain-saw workers whether or not they had Raynaud's phenomenon.

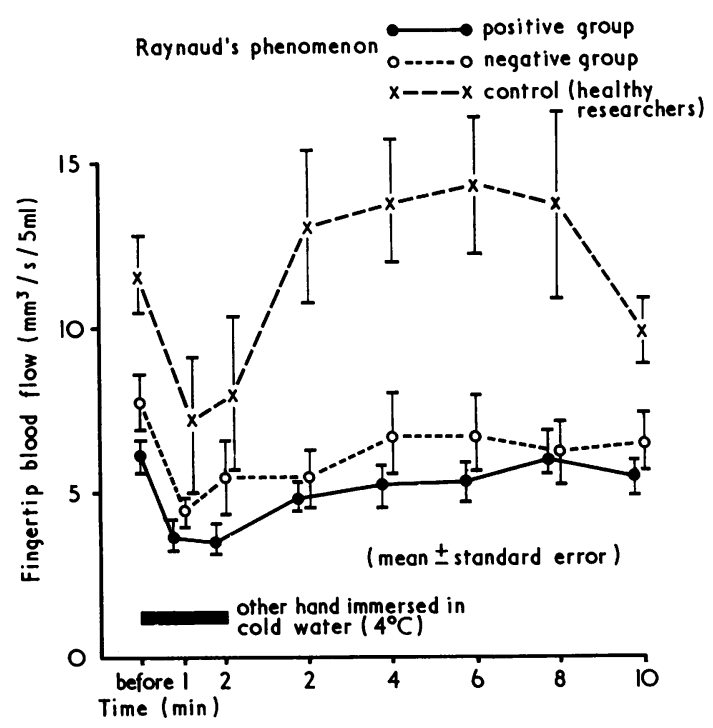

FIG. 1. Fingertip blood flow.

\section{Photomicrography of capillary vessels of fingernail bed}

Photomicrography of the fingernail bed was used to determine the diameter of the capillary vessels. The results were classified into three types: (a) normal, 15-20 $\mu$ in diameter, (b) spastic type, $\leqslant 15 \mu$, and (c) atonic type, $\geqslant 20 \mu$. The incidence of the three types in both the positive and negative groups was compared. The spastic type occurred in 11 out of 13 $(84.6 \%)$ of the positive group, and in 2 out of 8 $(25.0 \%)$ of the negative group. The $\chi^{2}$ test with 1 degree of freedom and applying Yates' correction gave a value of $5.15(0.01<P<0.05))$.

\section{Iontophoresis}

The plethysmogram after noradrenalin iontophoresis was rounded and the mean amplitude corresponded to $4.3 \mu \mathrm{l}$ in the Raynaud's phenomenon positive group. In the negative group the 
plethysmogram was sharp and the mean amplitude corresponded to $7.4 \mu \mathrm{l}$. When histamine iontophoresis was carried out subsequently, the pulsewave amplitude of the negative group increased above the amplitude of the positive group. The pulse-wave amplitude at the time of histamine iontophoresis was compared with that before histamine iontophoresis. Figure 2 shows the change of pulse-wave amplitude using the amplification factor (the percentage increased over the pulse-wave amplitude in noradrenalin iontophoresis) and current intensity.

\section{Excretion of urinary VMA}

The excretion of urinary VMA (metabolite of catecholamine) was determined to examine for any action of the sympathetic nervous system on the appearance of Raynaud's phenomenon. The excretion of urinary VMA was $5.0 \pm 2.2 \mathrm{mg} /$ day

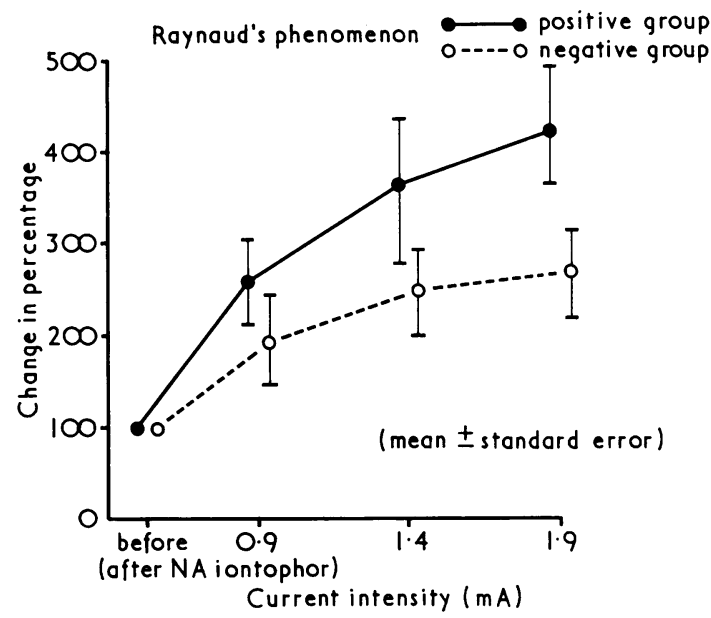

FIG. 2. Change of pulse-wave amplitude in histamine iontophoresis. (mean \pm standard error) in the Raynaud's phenomenon positive group, and $4.4 \pm 1.8 \mathrm{mg} /$ day in the negative. The differences were not statistically significant. In seven healthy researchers the VMA determined simultaneously was $5 \cdot 2 \pm 2 \cdot 1 \mathrm{mg} /$ day.

\section{Electromyograms and $x$-rays}

Possible evidence of damage to the median, radial, and ulnar nerves was sought by electromyography. As an abnormal appearance on the electromyogram, complex NMU voltage was observed. The abnormal appearance was seen in 5 out of $13(38.4 \%)$ in the positive group and in 1 out of $8(12.5 \%)$ in the negative.

Abnormal appearances on $x$-ray films were seen in 3 out of $13(23.1 \%)$ of the positive group, and in 1 out of $8(12.5 \%)$ of the negative. The abnormal findings on $x$-ray films were as follows: deformity of the elbow joints, and atrophy of the phalanges, wrist, metacarpal bone, etc. Abnormal findings on both the electromyogram and the $x$-ray were observed in one subject in the positive group and in none in the negative.

\section{Analysis of serum protein}

The serum protein results are shown in Table 1. Total serum protein and serum albumin results were not abnormal in either group. Disturbance of the peripheral circulatory system can be produced by cryoglobulin and on exposure to cold. However, cryoglobulin was scarcely detected, and the cold haemagglutination reaction was almost negative. From the figures for $\alpha_{2}$-globulin it was suggested that it might be useful to measure haptoglobin, which is the main component of $\alpha_{2}$-globulin. The haptoglobin was significantly increased in the positive group $(t=1.937, \mathrm{P}<0.05)$. The higher value of haptoglobin seemed to be an expression of an individual tension state.

In the immunoglobulins there was a higher

TABLE 1

Pattern of Serum Protein Results: Mean \pm S.D.

\begin{tabular}{|c|c|c|c|c|c|c|c|c|}
\hline & \multirow{2}{*}{$\begin{array}{c}\text { Raynaud's } \\
\text { phenomenon }\end{array}$} & \multirow{2}{*}{$\begin{array}{c}\text { Total } \\
\text { protein }\end{array}$} & \multirow{2}{*}{ Albumin } & \multicolumn{4}{|c|}{ Globulin } & \multirow{2}{*}{$\begin{array}{c}\text { Hapto- } \\
\text { globin } \\
(\mathrm{mg} / d l)\end{array}$} \\
\hline & & & & $\alpha_{1}$ & $\alpha_{2}$ & $\beta$ & $\gamma$ & \\
\hline $\begin{array}{lr}\begin{array}{l}\text { Measured } \\
(\mathrm{g} / \mathrm{dl})\end{array} & \text { value } \\
\text { Mean } \pm \text { S.D. } & \ldots\end{array}$ & $\begin{array}{l}\text { Positive } \\
\text { Negative }\end{array}$ & $\begin{array}{l}7 \cdot 4 \pm 0 \cdot 5 \\
7 \cdot 4 \pm 0 \cdot 4\end{array}$ & $\begin{array}{l}4.4 \pm 0.4 \\
4 \cdot 4 \pm 0.4\end{array}$ & $\begin{array}{l}0.25 \pm 0.05 \\
0.25 \pm 0.06\end{array}$ & $\begin{array}{l}0 \cdot 81 \pm 0 \cdot 10 \\
0.73 \pm 0.16\end{array}$ & $\begin{array}{l}0.80 \pm 0.12 \\
0.86 \pm 0.13\end{array}$ & $\begin{array}{l}1 \cdot 2 \pm 0 \cdot 1 \\
1 \cdot 1 \pm 0 \cdot 2\end{array}$ & $\begin{array}{l}138 \pm 45 \\
95 \pm 51\end{array}$ \\
\hline $\begin{array}{l}\text { Percentage of sub- } \\
\text { jects judged to be } \\
\text { abnormal } \\
\text { (no. in parentheses) }\end{array}$ & $\begin{array}{l}\text { Positive } \\
\text { Negative }\end{array}$ & $\begin{array}{c}0 \\
(0 / 13) \\
0 \\
(0 / 8)\end{array}$ & $\begin{array}{c}0 \\
(0 / 10) \\
0 \\
(0 / 8)\end{array}$ & $\begin{array}{c}0 \\
(0 / 10) \\
0 \\
(0 / 8)\end{array}$ & $\begin{array}{c}40 \\
(4 / 10) \\
13 \\
(1 / 8)\end{array}$ & $\begin{array}{c}10 \\
(1 / 10) \\
0 \\
(0 / 8)\end{array}$ & $\begin{array}{c}0 \\
(0 / 13) \\
0 \\
(0 / 8)\end{array}$ & $\begin{array}{c}39 \\
(5 / 13) \\
13 \\
(1 / 8)\end{array}$ \\
\hline
\end{tabular}


proportion with raised IgM in the positive group than in the negative group (Table 2). Moreover, the subjects in the negative group, in whom an increase of IgM was discovered, developed Raynaud's phenomenon seven to nine months after this measurement.

\section{Analysis by discriminant function}

Analysis by discriminant function was attempted to discriminate the positive and negative subjects apart from attacks. The indices chosen were: (1) fingertip blood flow as a measure of circulatory function (the value obtained at the second minute during immersion in cold water $\left(4^{\circ} \mathrm{C}\right.$ ) was used); (2) urinary VMA; and (3) haptoglobin. When $\mathbf{B}_{1}, \mathbf{B}_{2}$, and $\mathbf{B}_{3}$ were assigned to the value of each determination, (1) to (3), $\mathrm{Y}=-0.2203 \mathrm{~B}_{1}+0.0613 \mathrm{~B}_{2}+0.6647 \mathrm{~B}_{3}$, $Y_{G}=-0.0503\left(Y_{G}:\right.$ critical value of discrimination); the probability of false discrimination was $3 \%$ (estimated probability $\operatorname{Pr}(\mathrm{h}>t)=0.03$, assuming normal distribution).

\section{Discussion}

Raynaud's phenomenon, neuritis, and damage to the bones and perhaps muscles may occur from the use of vibrating tools. However, it is difficult to diagnose Raynaud's phenomenon between attacks. The objects of this study, have been first, the early diagnosis of Raynaud's phenomenon and, secondly, investigation of the pathogenesis.

Although a provocation test has been used for the diagonsis of Raynaud's phenomenon, the rate of provoked cases is not always $100 \%$. In previous experiments in which hands were immersed in cold water $\left(4^{\circ} \mathrm{C}\right)$ for 1 minute at room temperature $\left(6^{\circ} \mathrm{C}\right)$, we found the rate of provoked cases was $78.5 \%$ (Okada, Yamashita, and Ueda, 1967). de Takats and Fowler (1962) have conducted temperature studies by the immersion of hands in cold water after nerve block or reflex heat. The skin temperature of the finger in which Raynaud's phenomenon was provoked was not always lower than in the control finger in which Raynaud's phenomenon was not provoked (Okada et al., 1967).

Mendlowitz and Naftchi (1959) reported that patients could be divided into two groups, namely, those with digital vascular obstruction and normal vasomotor tone, and those without obstruction but with heightened vasomotor tone. We did not look for the existence of obstruction. Our results on digital blood flow, even before immersion in cold water, showed that the volume of digital blood flow was low not only in the Raynaud's phenomenon positive group but also in the negative group, who also were users of vibrating tools. Photomicrography of the capillary vessels of the fingernail bed revealed a higher incidence of spastic type in the positive group. But the difference between the two groups for urinary VMA, a final metabolite of epinephrine and norepinephrine (Armstrong, McMillan, and Shaw, 1957), was not statistically significant. However, from the result of discriminant function analysis in which urinary VMA, digital blood flow, and haptoglobin were used as indices, it is considered that they are useful in differentiation.

We found that Raynaud's phenomenon positive and negative subjects can be discriminated between attacks by iontophoresis alone although this technique does require specialized apparatus and some experience.

Katsunuma, Suzuki, and Hasegawa (1963) reported that attacks of 'white finger' and abnormality in electromyography might be independent of each other. In our study, abnormality in electromyography and $x$-ray appearance of the bones and joints was observed in both the Raynaud's phenomenon positive and negative groups, but at a higher rate in the positive group. It may be that those abnormalities might result from the direct operation of the vibration on the peripheral nervous system, the bones, and the joints independently of any action on the vascular system or its nerve supply.

Various hypotheses have been advanced to explain the pathogenesis of Raynaud's phenomenon of occupational origin. Magos and Okos (1963)

TABLE 2

IMMUNOGLOBULIN RESULTS

\begin{tabular}{|c|c|c|c|c|c|c|c|c|c|c|c|}
\hline & & & & & & & & $\begin{array}{c}\text { Raynaud's } \\
\text { phenomenon }\end{array}$ & $I g G$ & $\operatorname{Ig} A$ & $\operatorname{Ig} M$ \\
\hline $\begin{array}{l}\text { Percentage of subjects juc } \\
\text { (nos. in parentheses) }\end{array}$ & $\begin{array}{c}\text { ed to } \\
. .\end{array}$ & $\begin{array}{c}\text { eabn } \\
.\end{array}$ & $\begin{array}{r}\text { mal } \\
.\end{array}$ & $\begin{array}{c}\text { e text) } \\
\ldots\end{array}$ & $\begin{array}{l}\cdots \\
\cdots\end{array}$ & $\begin{array}{l}\cdots \\
\cdots\end{array}$ & $\begin{array}{l}. \\
\cdots\end{array}$ & $\begin{array}{l}\text { Positive } \\
\text { Negative }\end{array}$ & $\begin{array}{c}15 \\
(2 / 13) \\
0 \\
(0 / 8)\end{array}$ & $\begin{array}{c}15 \\
(2 / 13) \\
0 \\
(0 / 8)\end{array}$ & $\begin{array}{c}46 \\
(6 / 13) \\
25 \\
(2 / 8)\end{array}$ \\
\hline Normal range (see text) & . & . & . & . & . & . & . & & $100 \pm 15$ & $100 \pm 15$ & $100 \pm 13$ \\
\hline
\end{tabular}

All figures are given by mean \pm S.D. 
suggested that long-term repetitive vibratory exposure might result in damage of the vessel walls, nerve endings, and biochemical regulation and that subsequently decreased cold dilatation and Raynaud's phenomenon occurred. Ashe, Cook, and Old (1962) reported hypertrophic and fibrotic changes of the small muscular coats of the arteries. Cold and vibration initiated a physiological spasm of the vessels in the area subjected to vibration that led to a functional hypertrophy of the vessels which could be triggered into spasm by cold. On the other hand, Gurdjian and Walker (1945) reported that no demonstrable organic change in the capillaries and arterioles of the fingertip had been demonstrated in biopsy studies. Our findings on the serum proteins suggest that there might be an immunological basis for the reaction.

This investigation was reported in part at the 16th International Congress on Occupational Health; it was supported by a Hokkaido scientific research grant.

\section{References}

Agate, J. N. (1949). An outbreak of cases of Raynaud's phenomenon of occupational origin. Brit. J. industr. Med., 6, 144-163.

Armstrong, M. D., McMillan, A., and Shaw, K. N. F. (1957). 3-Methoxy-4-hydroxy-D-mandelic acid, a urinary metabolite of norepinephrine. Biochim. Biophys. Acta (Amst.), 25, 422-423.

Ashe, W. F., Cook, W. T., and Old, J. W. (1962). Raynaud's phenomenon of occupational origin. Arch. environm. Hlth, 5, 333-343.

de Takats, G., and Fowler, E. F. (1962). Raynaud's phenomenon. J. Amer. med. Ass., 179, 1-8.
Gurdjian, E. S., and Walker, L. W. (1945). Traumatic vasospastic disease of the hand (white fingers). J. Amer. med. Ass., 129, 668-672.

Hamilton, A. (1918). A study of spastic anemia in the hand of stonecutters. Bull. No. 236, U.S. Department of Labor, Bureau of Labor Statistics.

Katsunuma, H., Suzuki, T., and Hasegawa, T. (1963). Electromyographical studies of pneumatic tool diseases. Jap. J. industr. Hlth, 5, 453-461.

Lewis, T. (1938). The pathological changes in the arteries supplying the fingers in warm-handed people and in cases of so-called Raynaud's disease. Clin. Sci., 3, 287-319.

- and Pickering, G. W. (1934). Observations upon maladies in which the blood supply to digits ceases intermittently or permanently, and upon bilateral gangrene of digits; observations relevant to so-called 'Raynaud's disease'. Clin. Sci., 1, 327.

Loriga, G. (1911). Il lavoro coi martelli pneumatici. Boll. Ispett. Lavoro, $2,35$.

(1934). Pneumatic tools. In Occupation and Health: Encyclopedia of Hygiene and Social Welfare, Vol. 2. International Labour Office, Geneva.

Magos, L., and Okos, G. (1963). Cold dilatation and Raynaud's phenomenon. Arch. environm. Hlth, 7, 402-410.

Mendlowitz, M., and Naftchi, N. (1959). The digital circulation in Raynaud's disease. Amer. J. Cardiology, 4, 580-584.

Miyake, H. (1961). Improvement on Sandler's determination method for urinary VMA and the implication of determining the compound by the improved method. Folia pharmacol. jap., 57, 594-610.

Okada, A., Yamashita, T., and Ueda, M. (1967). Studies on the Raynaud's phenomenon of occupational origin, I On the provocation of Raynaud's phenomenon and the recovery process of its appearance. Jap. J. industr. Hith, 9, 51-59.

Winsor, T. (1959). Peripheral Vascular Diseases. Thomas, Springfield, Illinois.

Received for publication December 10, 1970. 